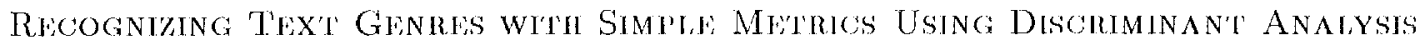

\author{
JUSSI KART,GIREN \\ jussiQsics.se \\ Swedish Institute of Computer Science \\ Box 1263, S-164 28 Kists, Stodkholm, Sweden
}

\author{
DOUGiass CUTPING \\ cuttingQapple.com \\ Apple Computer \\ Cupertino, (;A 950)14, USA
}

\begin{abstract}
A simple: method for catcgorizing texts in to pre-cletermined text genre catcgories using the statistical standard technique of discriminant antalysis is demonstrated with applicalion to the Brown corpus. Discriminant analysis makess it possible use a large number of paranchers that may be specific for a certain corpus or information strean, and combince them into a small number of functions, with the paraneters weighted on basis of how useful they are for discriminating text genres. An application to information retericval is aliscussed.
\end{abstract}

\section{Text 'Types}

There ane different types of text. "T'exts "about" the same thing may be in diftering gentes, of diflerent lypes, and of varying quality. 'lexts vary along several parant. eters, all relevant for the general information redrievil problem of matching reader needs and texts. Given this variation, in a text retrieval context the problems are (i) identifying genres, and (ii) choosing criteria to clus. ter texts of the sane genre, with predictable precision and recall. 'This should not be confused with the issue? of identifying topics, and choosing criteria that discriminate one topic from another. Althongl not orthogonal to genre-dependent variation, the variation that relatess directly to content and topic is along other dimensions. Naturally, there is co-variance. Texts about certain topics may only occur in certain genres, and texts in certain genres may only treat certain topics; most top. ics do, however, occur in sevoral genres, which is what interestis us licre.

Douglas Biber las studied text variation along several paranoters, and found that texts can be considered to vary along five dimensions. In his study, he clusters features according to covariance, to find underlying di mensions (1989). We wish to find a method for identifying casily computable parameters that rapidly chassify previously unseen texts in general classes and along a small set smaller than Biber's five of climensions, such that they can be explained in intuitively simple terns to the user of an information retrieval application. Our aim is to take a set of texts that has been selected by some sort of crude semantic andysis such as is typically performed by an information retrieval system and partition it further by genre or text type, and

\begin{tabular}{|c|c|c|}
\hline lixperiment 1 & lixperiment 2 & $\begin{array}{l}\text { Hxperiment } 3 \\
\text { (Brown categories) }\end{array}$ \\
\hline \multirow[t]{9}{*}{ I. Informative } & \multirow[t]{3}{*}{ 1. Tress } & A. Press: reportage \\
\hline & & 13. Press: editorial \\
\hline & & C. Pross: reviews \\
\hline & \multirow[t]{4}{*}{ 4. Misc: } & D. Religion \\
\hline & & lis sikils and Ilobbices \\
\hline & & T. Popular Jore \\
\hline & & G. Belles Jeteres etc \\
\hline & \multirow[t]{2}{*}{ 2. Nonlfiction } & 11. Gov doe \& misc. \\
\hline & & J. Wearned \\
\hline \multirow[t]{6}{*}{ I. Intaginative } & \multirow[t]{6}{*}{ 3. ]icitiont } & K. Gencral liction \\
\hline & & I. Mystery \\
\hline & & M. Scionce liction \\
\hline & & $\bar{N} . \bar{d} \mathrm{v} . \bar{W}$ Western \\
\hline & & P. Romance \\
\hline & & 12. IIuinos \\
\hline
\end{tabular}

'lable: 1: Categories in the Brown Corpus

to display this variation as simply as possible in one or two dimensions.

\section{Method}

We start by using features similar to those first investigated by Biber, but we concentrate on those that are casy to compute assuming we have a part of speech latgger (Cutling ef al, 1992; (hurch, 1988), such as such as third person pronoun occurence rate ins opposed to 'general hedges' (Biber, 1989). More and more of Biber's features will be available with the advent of more proficient analysis prograns, for instance if conplete surface syntactic parsing were performed before categorization (Voutilanen \& Tapanainen, 1993).

We then use discrinninant analysis, a technique from (eescriptive statistics. Discriminant analystis takes a set of precategorized individuals and data on their vallat tion on a munter of parandelers, and works out a sot discriminan! functions which distinguishes betweon the groups. These functions can then be used to predict the calegory menherships of new individuals based on their paraneter scores (Tatsuoka, 1971; Mustonen, 1965).

\section{Evaluation}

fior datia we used the Brown corpus of linglish text samples of uniform length, categorized in several categories 


\begin{tabular}{|ll|}
\hline Variable & Range \\
\hline Adverb count & $19-157$ \\
Claracter count & $7601-12143$ \\
Jong word count (>6 chars) & $168 \cdots 838$ \\
Preposition count & $151-\mathbf{4 3 3}$ \\
Second person pronoun count & $0-89$ \\
"Iherefore" count & $0-11$ \\
Words per scntence average & $8.2 \cdots 53.2$ \\
Chars / scntence average & $34.6-266.3$ \\
First person pronoun count & $0-156$ \\
"Me" count & $0 \cdots 30$ \\
Present participle count & $6 \cdots 101$ \\
Sentence count & $40-236$ \\
Type / token ratio & $14.3-53.0$ \\
"I" count & $0-120$ \\
Character per word average & $3.8-5.8$ \\
"It" count & $1-53$ \\
Noun count & $243-751$ \\
Present verb count & $0-79$ \\
"lhat:" count & $1-72$ \\
"Which" count & $0-40$ \\
\hline
\end{tabular}

'Table 2: Parameters for Discriminant Analysis

\begin{tabular}{|l|l|r|}
\hline Category & Items & Frrors \\
\hline I. Informative & 374 & $16(4 \%)$ \\
II. Imaginative & 126 & $6(5 \%)$ \\
\hline Total & 500 & $22(4 \%)$ \\
\hline
\end{tabular}

Table 3: Categorization in 'l'wo Categories

as seen in table 1. We ran discriminant analysis on the texts in the corpus using several different features as seen in table 2. We used the SPSS system for statistical data analysis, which has as one of its features a complete discriminant analysis (SPSS, 1990). The discriminant function extracted from the data by the analysis is a linear combination of the parameters. 'To categorize a set into $N$ categories $N-1$ functions need to be determined. However, if we are content with being able to plot all categories on a two-dimensional plane, which probably is what we want to do, for ease of exposition, we only use the two first and most significant functions.

\section{2 categories}

In the case of two categories, only one function is neccssary for determining the category of an item. 'The function classified 478 cases correctly and misclassificd 22 , out of the 500 cases, as shown in table 3 and figure 1.

\section{4 categories}

Using the three functions extracted, 366 cases were correctly classified, and 134 cases were misclassified, out of the 500 cases, as can be seen in table 4 and figure 2 . "Miscellaneous", the most problematic category, is a loose grouping of different informative texts. 'The single most problematic subsubset of texts is a subsel of eighteen non-fiction toxts labeled "learned/hurnanities". Sixteen of them were misclassified, thirteen as "miscellaneous".

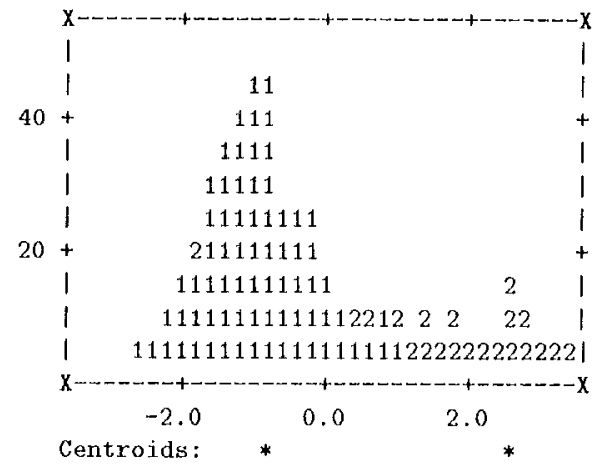

Figure 1: Distribution, 2 Categories

\begin{tabular}{|l|l|r|}
\hline Catcgory & ltems & Frrors \\
\hline 1. Press & 88 & $15(17 \%)$ \\
2. Non-fiction & 110 & $28(25 \%)$ \\
3. Fiction & 126 & $6(5 \%)$ \\
4. Misc. & 176 & $68(47 \%)$ \\
\hline Total & 500 & $134(27 \%)$ \\
\hline
\end{tabular}

Table 4: Categorization in Four Categorics

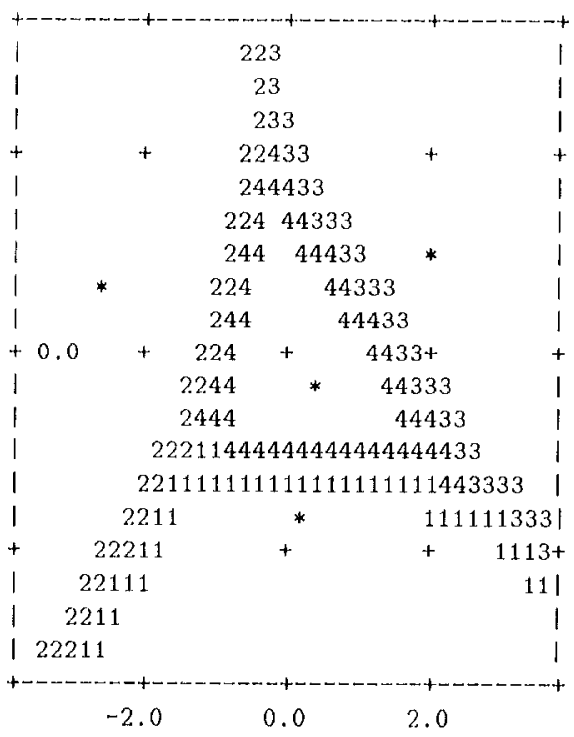

Ligure 2: Distribution, 4 Catcgories 


\section{5 (or 10) categorios}

Using the fourteen functions extracted, 258 cases were correctly classified and 242 cases misclatssilied ont of the 500 cases, as shown in talzle 5. Trying to distin. gutush between the clifferent lypes of' fiction is expensive in terms of errors. If the fiction subcategories were collaysed there only would be ten categories, and the error rate for the categoriation would improve as shown in the "revised total" record of the table. "The "learned/humanities" subcategory is, as before, problematic: only two of the eighteen itens were correctly classified. 'The others were most often misclassified as "Religion" or "Belles Letires".

\section{Validation of the Technique}

It is important to note that this experiment does not clain to sloow how gentess in fact differ. What we show is that this sort of technicue can be used to determine which parameters to use, given a set of them. Wo dicl not use a test set disjoint from the training set, and we do not claim that the finctions we had the method extract from the data are useful in themselves. We discuss how well this method categorizes a set text, given a set of catcgories, and given a set of paraneters.

'I'he error rates climb steeply with the number of categries tested for in the corpuss we used. This may have to do with how the calesgries are chosen and defined. For instance, distinguishing between different. types of fiction by formal or stylistic criteria of this kind may just be something we should not attempt: the fiction types are naturally defined in terms of their coutent, after all.

The statistical technique of factor analysis can be used to discover categories, like Biber has done. 'The problem with using antonatically derived categories is that even if they are in at sense real, meaning that they are supported by data, they may be diflecult to explain for the umenthusiastic layman if the aim is to use the teclunicue in retrieval tools.

Other criteria that should be shodied are second and higher order statistics on the respective paraneters. Certain paraneters probably vary more in cortain text types than others, and they may have at skewed distribution as well. 'This is not diffieult to determine, although the standard methods do not support anto inatic determination of standard deviation or skewness as discrimination criteria. 'logether with the investi. gation of several hitherto untried parancters, this is a next step).

\section{Readability Indexing}

Not mrelated to the study of genre is the study of readability which aims to categorize texts according to their suitability for assumed sets of assmmed readers. There is a wealth of formula to compute readability. Most commonly they combine casily computed text measures, lypically average or sampled average: sch tence length combined with similarly computed word lengtl, or incidence of words not on a specified "ensy word list." (Chall, 1948; Rlate, 1963). In spite of Chall's warnings about injudicious application to writing tasks, readability measurement has navely come to be used as a prescriptive metric of good writing ats a tool for writers, and has thus come into some disrepute among text rescarchers: Our sunall study confirms the basic lindings of the carly readability studies: the most important factors of the ones wo tested are word length, sentence length, and different derivatives of these two parameters. As long as readability indexing schemes are used in descriptive applications they work well to discrininate between text types.

\section{Application}

The technique shows pratical promise. 'The territo rial maps shown in figures 1, 2, and 3 are intuitively useful tools for displaying what typo a particular text is, compared with other existing texts. The technique demonstaled above has an obvious application in information retrieval, for picking out interesting texts, if content based methods select a too large set for easy manipulation and browsing (Cutting el al, 1992).

In any specific application area it will be unlikely that the text database to be accessed will be completely free form. 'Ithe texts under consideration will probably be specilie in some way. General text types may be useful, but quite probably there will be a domain- or fiest-specific text typology. In an envisioned applicattion, a user will comploy a cascade of filters starting with filtering by topic, and continuing with filters by genre? or text type, and ending by filters for text quality, or other tentative finer-grained gualifications.

\section{The IntFilter Project}

The [nt Filter Project at the departments of Computer ancl Systems Sciences, Compulational linguistics, and Psychology at Stockholm University is at present shudy. ing bexts on the UStink I News conferencing systom. The project at present studies texts which appoar on several different types of USENFI' News conferences, and investigates how well the classilication criteria and categories that experienced USWNE', News users report using (Intiliter, 1993) can be used by a newsreader system. To do this the project applies the method described here. The project uses categories such as "query", "comment", "announcement", "MAQ", and so forth, categorizing them using paraneters such as different types of lenglh measures, form word content, quole level, percentage quoled text and other USTN News specific parameters.

\section{Acknowledgements}

'Thanks to flans Karlgren, Gumnel Källgren, Geoff Nunberg, Jan Pedersen, and the Coling referees, who all have contributed with suggestions and methodological disconsions. 


\begin{tabular}{|l|l|l|r|}
\hline Category & Items & Errors & Miss \\
\hline A. Press: reportage & 44 & $11(25 \%)$ & $\mathrm{I}$ \\
B. Press: editorial & 27 & $8(30 \%)$ & $\mathrm{A}$ \\
C. Press: reviews & 17 & $4(24 \%)$ & $\mathrm{B}$ \\
J. Religion & 17 & $8(47 \%)$ & $\mathrm{G}$ \\
E. Skills and Hobbies & 36 & $17(47 \%)$ & $\mathrm{J}$ \\
F. Popular Lore & 48 & $32(67 \%)$ & $\mathrm{G}, \mathrm{E}$ \\
G. Belles Lettres, Biographies etc. & 75 & $49(65 \%)$ & $\mathrm{D}, \mathrm{B}, \mathrm{A}$ \\
H. Government documents \& misc. & 30 & $9(30 \%)$ & $\mathrm{J}$ \\
J. Learned & 80 & $32(40 \%)$ & H,I),G,F \\
K. General Fiction & 29 & $16(55 \%)$ & fiction \\
I. Mystcry & 24 & $12(50 \%)$ & $-"-$ \\
M. Science Fiction & 6 & $1(17 \%)$ & $-"-$ \\
N. Adventure and Western & 29 & $18(62 \%)$ & $-"-$ \\
P. Romance & 29 & $22(76 \%)$ & $-"-$ \\
R. Humor & 9 & $3(33 \%)$ & $-"-$ \\
\hline Total & 500 & $242(48 \%)$ & \\
\hline Fiction (From previous table) & 126 & $6(5 \%)$ & \\
Revised total & 500 & $178(35 \%)$ & \\
\hline
\end{tabular}

Table 5: Categorization in 15 Categories

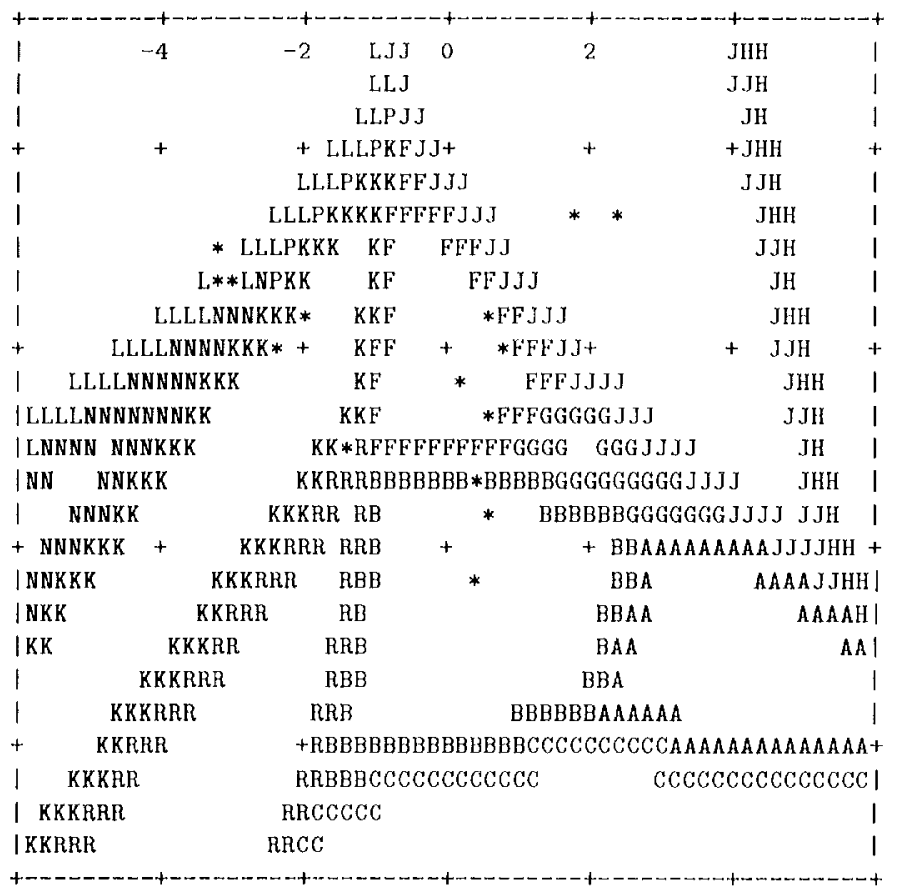

Figure 3: Distribution, 15 Categories * Indicates a group centroid. 


\section{References}

Douglas Biber 1989. "A typology of linglish texte", Linguistics, 27:3-43.

Jeanne S. Chall 1948. Readability, Olio State Univ.

Kenneth Church 1988. " $\Lambda$ Stochastic Parts of Spech and Nonn Phrase Parser for Unrestricted l'ext", Procs. end ANLI, Austir.

Douglass Cutting, Julian Kupiec, Jan Pedersen, and Penelope Sibun $1992 . \quad$ "A Practical P'art-of-speech 'laggee", procs. 3 rol ANLI', 'Thento.

Donglass Cutting, D. Karger, Jan Pedersen, and John Tukey 1992. "Scatter/Gather: $\Lambda$ Cluster-basexl Approach to Browsing laarge Dorument Collections" Procs. Slall'o2.

IntFilter 1993.

Working I'apers of the Indlitler Project, available by gopher from dsv.su.se:/pub/IntFilter.

George R. Klare 1963. The Measuremcnt of Readabitity, lowa Univ press.

W. N. Francis and I'. Kučera 1982. Frequency dnalysis of Einglish Usage, Iloughtum Millin.

Seppo Mustonen 1965. "Multiple Discriminant Analy sis in Linguistic: Problems", Statistical Methots in linguistics, 4:37-44.

M. M. Tatsmoka 1971. Mullivariate Analysis, New York:John Wiley \& Sons.

Atro Voutilainen and Pasi Tapanainen 1993. "Ambi guity resolution in a reductionistic: parser", Procs, oth liuropean $A C \%$, Utrechl.

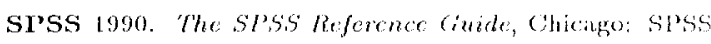
Inc. 